\title{
V. Experimental determination of magnetic induction in an elongated spheroid
}

\author{
Prof. D.N. Mallik
}

To cite this article: Prof. D.N. Mallik (1908) V. Experimental determination of magnetic induction in an elongated spheroid , Philosophical Magazine Series 6, 15:85, 65-68, DOI: 10.1080/14786440809463747

To link to this article: http://dx.doi.org/10.1080/14786440809463747

曲 Published online: 16 Apr 2009.

Submit your article to this journal $₫$

Џ Article views: 3

Q View related articles $₫$ 


\section{[ 65 ]}

V. Experimental Determination of Magnetic Induction in an Elongated Spheroid. By Prof. D. N. MaLLIK*.

1. T $\mathrm{N}$ a paper on the magnetic induction in a spheroid due to a coil carrying current (Phil. Mag. Oct. 1907), $I$ proved that if $\mathrm{M}$ be the induction at any point of such a spheroid,

$$
\begin{aligned}
\mathrm{M} & =\frac{p e}{a^{2}}(1+4 \pi k) 2 \pi m i\left[1+\frac{2 e^{2} c \log \left(1+\frac{\lambda}{c}\right)}{3 \pi \lambda\left(1+\frac{a^{2}}{c^{2}}\right)}-\frac{2}{\pi}\right] \\
& =\mathrm{A} p, \text { say, }
\end{aligned}
$$

$\therefore$ if $\mathrm{B}=$ total magnetic induction over the semi-ellipsoid, $\mathrm{B}=\int \mathrm{M} d \mathrm{~S}=\mathrm{A} \int p d \mathrm{~S}=\mathrm{A} a^{2} \int d x$

$$
=(1+4 \pi k) 2 \pi m i\left(1-\frac{4}{3 \pi}\right) \int d x, \text { nearly, }
$$

where $d \mathrm{~S}$ is an element of surface, and $d x$ an element of the major axis ;

i.e. $\frac{d \mathrm{~B}}{d x}=$ const.

In this form it is suitable for experimental verification, and $I$ have made a series of experiments to test its accuracy.

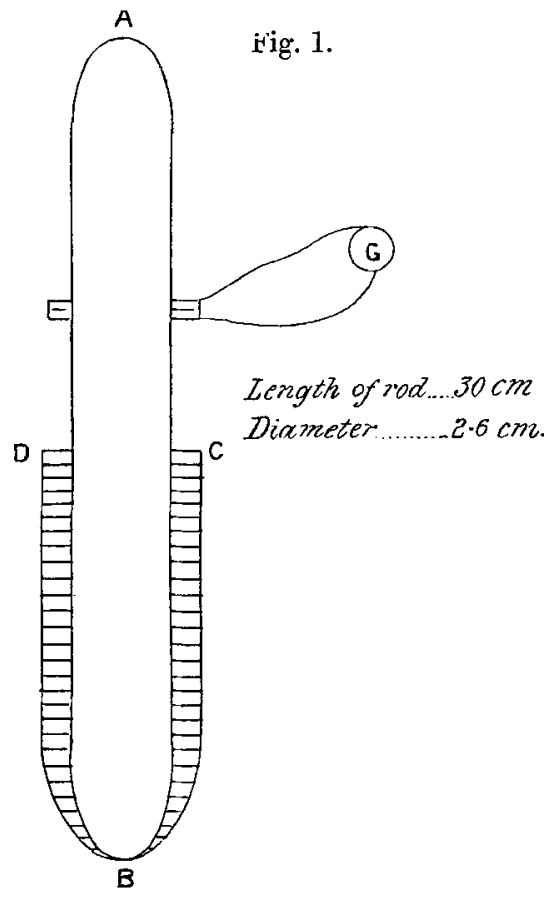

2. For this purpose, a rod $A B$ (fig. 1) was prepared * Communicated by the Author.

Phil. Mag. S. 6. Vol. 15. No. 85. Jan. 1908. 
66 Prof. D. N. Mallik : Experimental Determination

approximately spheroidal in form of very mild Bessemer steel well annealed, and the coil DC was wound round a thin wooden cap which just fitted it to half its length.

A current, the constancy of which was indicated by an ammeter, being passed through the coil, the soft steel rod was magnetized, and the object of the experiments was to explore the magnetic induction over the projecting portion of the rod.

3 . In order to do this, a thin coil $\frac{1}{4}$ inch in thickness having 36 turns (six turns, six deep), in series with a ballistic galvanometer, was slipped over the rod and placed at different positions beginning with middle of rod (the zero position), and corresponding throws on the reversal of current were noted. In the preliminary experiments (I. and II.) the thin coil was placed at random at different positions which were read

Fig. 2.

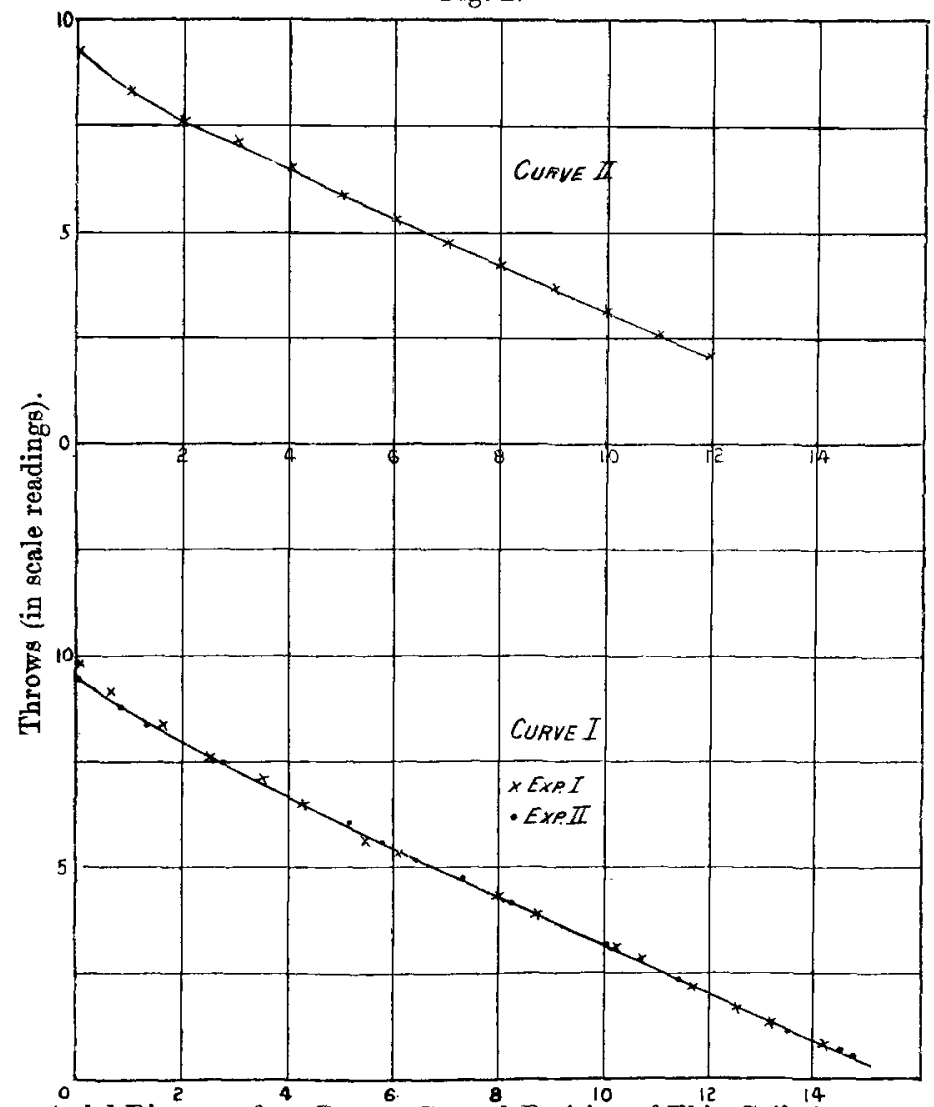

Axial Distances from Zero or Central Position of Thin Coil (in cms.).

off by means of a telescope. The results are represented by Curve I., fig. 2, in which abscissa represent distances from 
the zero position, and ordinates the throws obtained at corresponding positions.

4. In the final experiments the thin coil was moved up, a centimetre at a time, by means of a mechanical arrangement allowing of the actual displacement being read off on a vertical scale parallel to the axis of the rod. The following table gives the results obtained after a slight correction on account of the direct action of the magnetizing coil.

\begin{tabular}{|c|c|c|c|c|}
\hline $\begin{array}{l}\text { Distance } \\
\text { from zero. }\end{array}$ & $\begin{array}{l}4 \times \text { throw. } \\
\text { Exp. IIT. }\end{array}$ & $\begin{array}{l}4 \times \text { throw. } \\
\text { Exp. IV. }\end{array}$ & $\begin{array}{l}\text { Mean } \\
\text { throw. }\end{array}$ & $\begin{array}{c}\text { Throw } \\
\text { per em. of rod. }\end{array}$ \\
\hline $\begin{array}{c}0 \\
1 \\
2 \\
3 \\
4 \\
5 \\
6 \\
7 \\
8 \\
9 \\
10 \\
11 \\
12\end{array}$ & $\begin{array}{l}37 \cdot 6 \\
34 \cdot 95 \\
32 \cdot 2 \\
29 \cdot 35 \\
26 \cdot 6 \\
24 \cdot 1 \\
21 \cdot 4 \\
19 \cdot 4 \\
17 \cdot 12 \\
15 \cdot 1 \\
13 \\
10 \cdot 73 \\
8 \cdot 9\end{array}$ & $\begin{array}{l}36 \cdot 7 \\
33 \cdot 55 \\
31 \cdot 05 \\
28 \cdot 4 \\
26 \cdot 1 \\
23 \cdot 7 \\
21 \cdot 35 \\
19 \cdot 25 \\
17 \cdot 16 \\
14 \cdot 8 \\
12 \cdot 8 \\
10 \cdot 63 \\
8 \cdot 6\end{array}$ & $\begin{array}{l}9 \cdot 29 \\
8 \cdot 56 \\
7 \cdot 9 \\
7 \cdot 22 \\
6 \cdot 59 \\
5 \cdot 97 \\
5 \cdot 34 \\
4 \cdot 83 \\
4 \cdot 28 \\
3 \cdot 73 \\
3 \cdot 29 \\
2 \cdot 67 \\
2 \cdot 19\end{array}$ & $\begin{array}{l}73 \\
.66 \\
\cdot 68 \\
\cdot 63 \\
.62 \\
.63 \\
.51 \\
.55 \\
.55 \\
.51 \\
.55 \\
.48\end{array}$ \\
\hline
\end{tabular}

[In Exp. III. the exploring coil was moved from the zero position, and in Exp. IV. to the zero position.]

The results are also plotted in the Curve II. It will be* seen that both sets of experiments give practically identical results, viz., that the curve is straight with a slight upward trend for the first three cms. from the zero. In order to explain this, we note that the rod is not altogether spheroidal in form, but is practically a cylinder with a rounded off end, so that the small coil for the first few centimetres from the zero position embraces more lines of force than if the rod were accurately spheroidal. We conclude therefore that the formula $(\$ 1)$ is experimentally verified for an elongated spheroid. It will therefore be necessarily also true of a cylindrical rod with rounded off ends, if the rod is sufficiently thin.

5. Further it is seen that in the latter case the lines of force are radial and uniformly distributed.

Moreover, if $m$ be the total amount of induced magnetism over such a cylinder,

$$
4 \pi m=\mathrm{B},
$$

and $\rho=$ linear density of this magnetism,

or

$$
\begin{gathered}
4 \pi \int \rho d r=\mathrm{B}, \\
\frac{d \mathrm{~B}}{d x}=\rho=\text { const. }
\end{gathered}
$$


or linear density of induced magnetism in a long thin cylinder due to a coil embracing half its length is constant.

6. The tormula being thus experimentally verified, it may obviously be used to find how the value of $k$ corresponding to different values of current, varies.

For this the small coil was placed in the central position and the throws of the galvanometer for different values of the current were noted. The following table gives the results of experiment.

$\begin{array}{cc}\text { Current in amperes. } & \text { Throw. } \\ \cdot 2 & 1 \cdot 05 \\ \cdot 4 & 2 \cdot 1 \\ \cdot 6 & 3 \cdot 15 \\ \cdot 8 & 4 \cdot 4 \\ 1 & 6 \\ 1 \cdot 2 & 7 \cdot 04 \\ 1 \cdot 4 & 8 \cdot 07 \\ 1 \cdot 6 & 9 \cdot 2 \\ 1 \cdot 8 & 10 \cdot 02 \\ 2 & 11 \cdot 55\end{array}$

These throws are plotted on a curve (fig. 3) in which these Fig. 3.

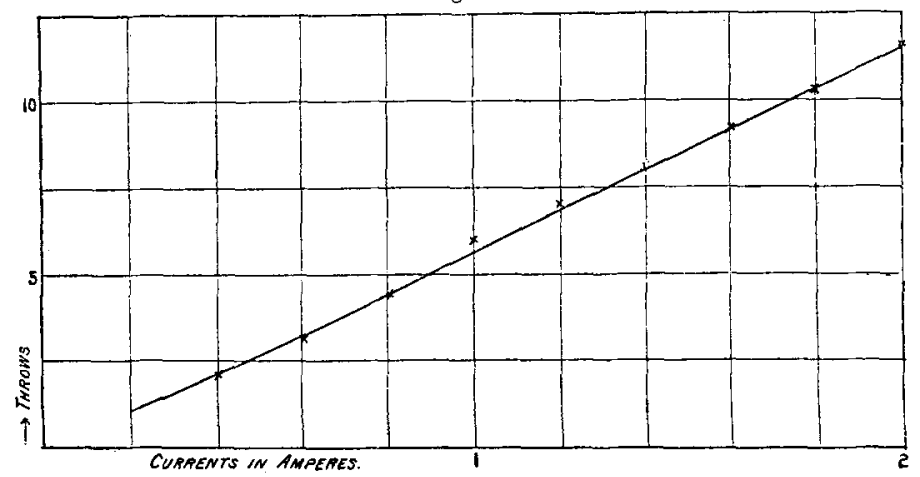

are abscissæ and the currents are ordinates. We see that up to current of $\cdot 8$ ampere $k$ is absolutely constant, and then begins to vary slightly with the current, the variation being at first inappreciable. Unfortunately, however, the effect of the current in heating the coil as well as the rod was so great when the current was over 2 amperes, that it was not thought desirable to proceed with the experiments for stronger currents without considerable modification in the apparatus.

I have to thank Prof. Trouton for permission to work at the University College Laboratory for the purposes of the above investigation. 